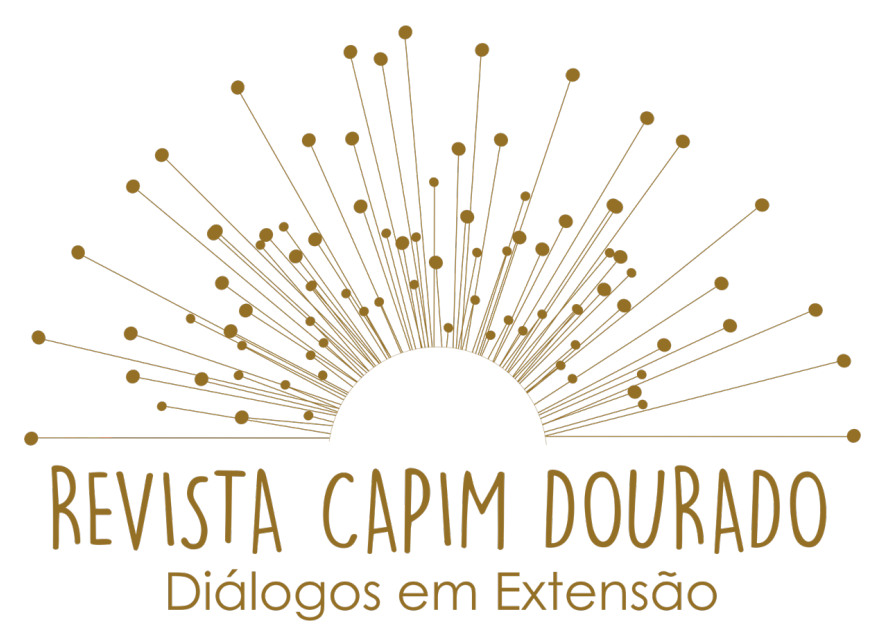

\title{
PADU ARAGUAÍNA: experiência do pré-enem comunitário
}

ARAGUAÍNA PADU: experience of the community pre-enemy

ARAGUAÍNA PADU: experiencia de la comunidad pre-enemiga

\section{Murilo Henrique S. de Paula ${ }^{1}$ \\ Kênia Gonçalves Costa ${ }^{2}$ \\ José Manoel Sanches da Cruz}

\section{RESUMO}

No objetivo de oferecer oportunidade, democratizando o acesso à universidade através de um projeto voltado para a comunidade estudantil de Araguaína, em março de 2018 teve-se início as atividades letivas do Cursinho pré-enem comunitário, com aulas oferecidas na Universidade Federal do Tocantins, campus de Araguaína, sendo: a) realizados nos finais de semana; b) trabalhando as 4 áreas do conhecimento incluindo redação; c) aulas ministradas pelos próprios acadêmicos da instituição. Com a ideia de procurar parcerias para o material pedagógico a ser seguido, foi fechado uma parceria com o cursinho prévestibular "Descomplica", que nos autorizou a utilizar o seu material Enem em 100 dias, que nele contém várias questões divididas por conteúdos que mais caiem no ENEM além de ter o material teórico das 4 áreas de conhecimento. Os resultados foram quali-quantitativos, no qual os números de inscritos para

\footnotetext{
1 Graduando em Geografia, Universidade Federal do Tocantins (UFT) Araguaína, Tocantins, murilo-paula@live.com.

2 Coordenadora do PADU, Professora Doutora, Universidade Federal do Tocantins (UFT) Araguaína, Tocantins, keniacost@.uft.edu.br.

3 Diretor, Professor Doutor, Universidade Federal do Tocantins (UFT) Araguaína, Tocantins, sanches@uft.edu.br.
} 


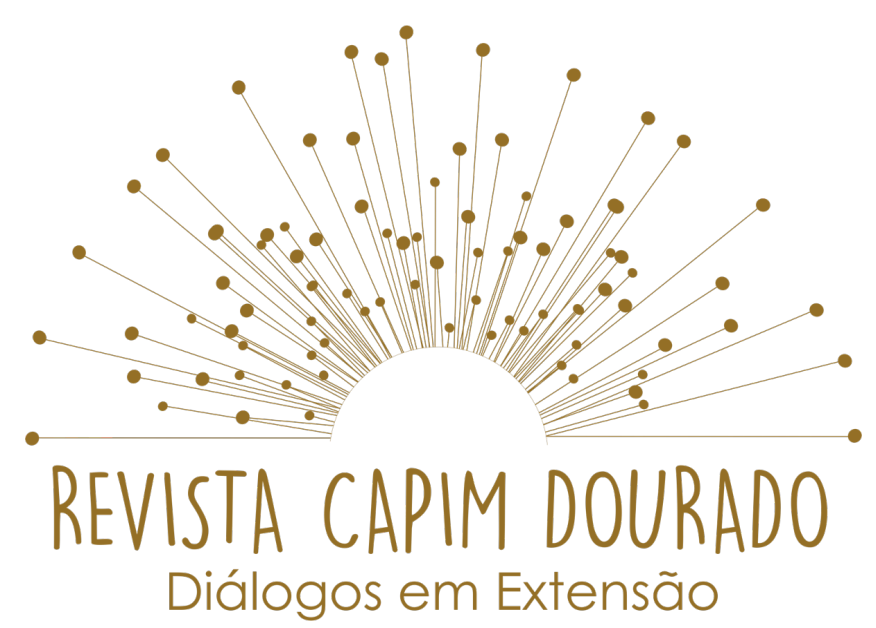

ISSN n² 2595-7341

Vol. 3, n. 1, Janeiro-Abril, 2020

DOI: http://dx.doi.org/10.20873/uft.2595-7341.2020v3n1p173

participarem como alunos do projeto, foram 498, ficando claro a importância desse projeto para a comunidade de Araguaína e com um resultado médio de mais de 80 alunos aprovados no ENEM e vestibulares de instituições de ensino superior, mostrando assim, um resultado satisfatório do projeto final.

PALAVRAS-CHAVE: Cursinho. Educação. Comunidade. Integração. ENEM.

\section{ABSTRACT}

In order to offer opportunities, democratizing access to the university through a project aimed at the student community of Araguaina, in March 2018 the teaching activities of the pre-enemy community course began, with classes offered at the Federal University of Tocantins, Araguaína campus, being: a) held on weekends; b) working on the 4 areas of knowledge including writing; c) classes taught by the institution's own academics. With the idea of looking for partnerships for the pedagogical material to be followed, a partnership was closed with the preuniversity course "Descomplica", which authorized us to use its Enem material in 100 days, which contains several questions divided by contents that most fall in ENEM besides having the theoretical material from the 4 areas of knowledge. The results were qualitative and quantitative, in which the number of enrolled to participate as students of the project was 498, making it clear the importance of this project for the community of Araguaína and with an average result of more than 80 students approved at ENEM and entrance exams of higher education institutions, thus showing a satisfactory result of the final project.

KEYWORDS: Short course. Education. Community. Integration. ENEM.

\section{RESUMEN}

Con el fin de ofrecer oportunidades, democratizando el acceso a la universidad a través de un proyecto dirigido a la comunidad estudiantil de Araguaína, en marzo 


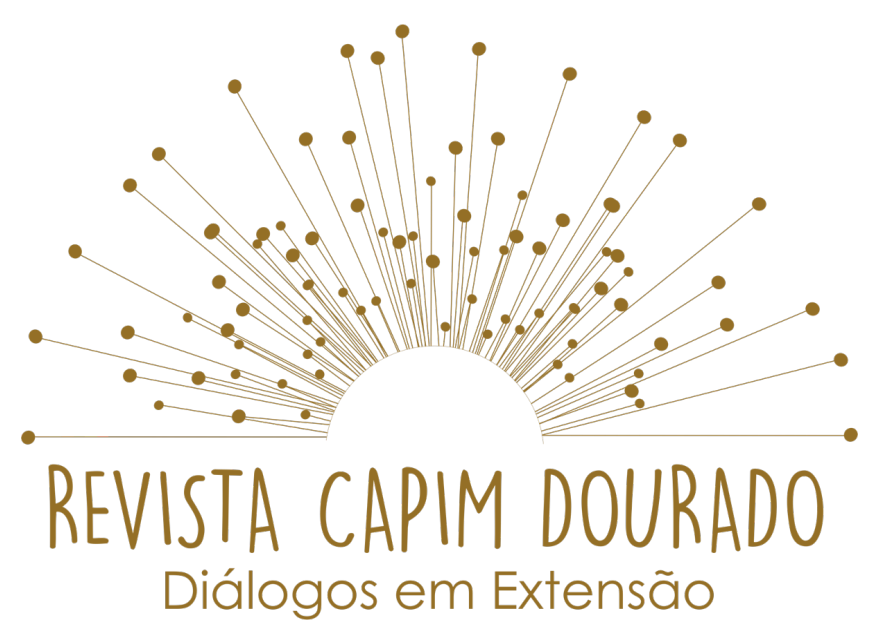

ISSN n² 2595-7341

Vol. 3, n. 1, Janeiro-Abril, 2020

DOI: http://dx.doi.org/10.20873/uft.2595-7341.2020v3n1p173

de 2018 se iniciaron las actividades docentes del curso comunitario pre-enemigo, con clases impartidas en la Universidad Federal de Tocantins, Recinto Araguaína, siendo: a) los fines de semana; b) trabajar en las 4 áreas de conocimiento, incluida la escritura; c) clases impartidas por académicos propios de la institución. Con la idea de buscar alianzas para el material pedagógico a seguir, se cerró una alianza con el curso preuniversitario "Descomplica", que nos autorizó a utilizar su material Enem en 100 días, el cual contiene varias preguntas divididas por contenidos que la mayoría cae en ENEM además de tener el material teórico de las 4 áreas de conocimiento. Los resultados fueron cualitativos y cuantitativos, en los que el número de inscritos para participar como alumnos del proyecto fue de 498, dejando en claro la importancia de este proyecto para la comunidad de Araguaína y con un resultado promedio de más de 80 alumnos aprobados en ENEM y exámenes de ingreso de instituciones de educación superior, mostrando así un resultado satisfactorio del proyecto final.

PALABRAS CLAVE: Curso corto. Educación. Comunidad. Integración. ENEM.

Recebido em: 01.10.2019. Aceito em: 09.10.2019. Publicado em: 01.01.2020. 


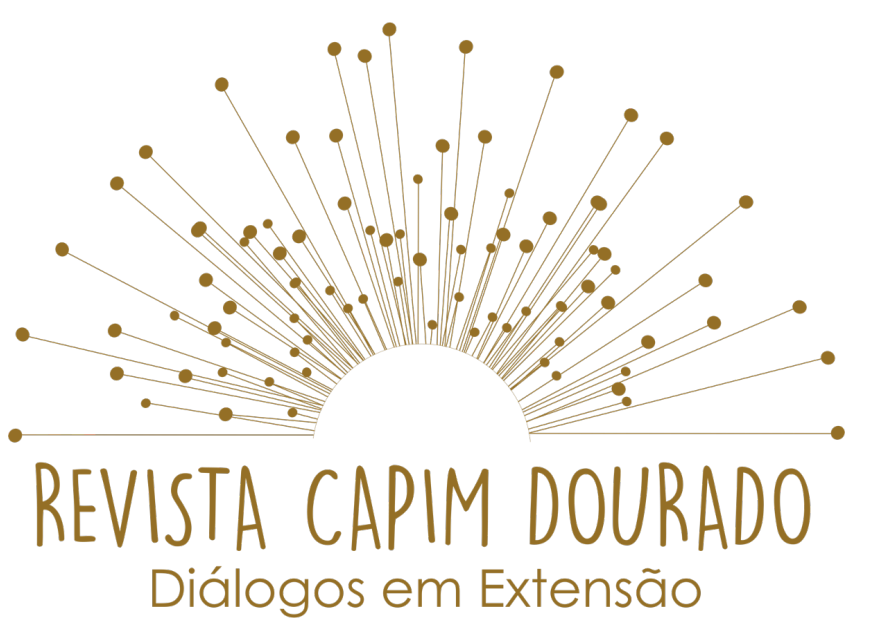

ISSN n² 2595-7341

Vol. 3, n. 1, Janeiro-Abril, 2020

DOI: http://dx.doi.org/10.20873/uft.2595-7341.2020v3n1p173

\section{INTRODUÇÃO}

O projeto do cursinho PADU Araguaína-UFT (Programa de Acesso Democrático à Universidade) (UFT, 2018), teve início em fevereiro com um total de 7 bolsistas e 4 professores voluntários divididos entre as 4 áreas do conhecimento e mais redação. O projeto iniciou com uma turma de 150 estudantes, que foram selecionados em um processo seletivo que teve 498 candidatos(as) e terminou em novembro de 2018 com uma turma média de 100 estudantes. $O$ intuito do projeto é oferecer aos estudantes das escolas públicas o acesso à universidade, oferecendo uma preparação para o ENEM (Exame Nacional do Ensino Médio), além de oferecer a oportunidade aos acadêmicos dos cursos de licenciatura do campus UFT Araguaína de obter a experiência de sala de aula, através do cursinho preparatório, qualificando ainda mais o acadêmico para a docência.

\section{METODOLOGIA}

Com início em suas atividades inicialmente com as inscrições e seleção dos 07 bolsistas e dos 150 estudantes, entre fevereiro a março realizado na instituição, as atividades letivas ocorreram de março para novembro de 2018, havendo uma pausa nas férias no mês de julho e retomando as atividades em agosto deste ano. No período de inscrições, houve um total de 498 inscritos, sendo que foram apenas 150 vagas oferecidas dentro da estrutura oferecida pela 


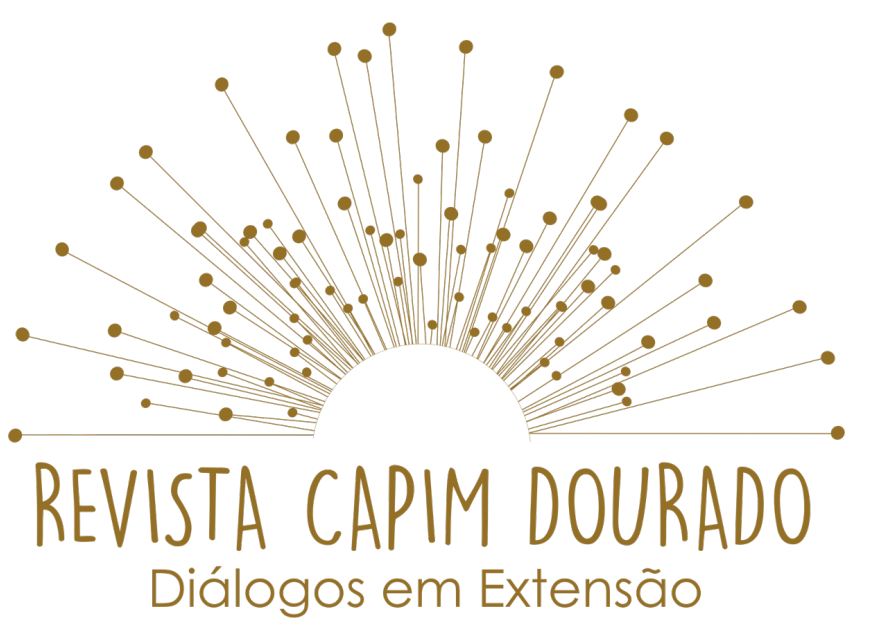

ISSN n² 2595-7341

Vol. 3, n. 1, Janeiro-Abril, 2020

DOI: http://dx.doi.org/10.20873/uft.2595-7341.2020v3n1p173

instituição, tornando necessário a realização de um processo seletivo devido ao grande número de inscritos.

Diante das condições para o processo seletivo, a metodologia utilizada foi verificar através do coeficiente discriminado no histórico escolar do último ano letivo do ensino médio do inscrito, selecionando 150 participantes para o projeto, os demais inscritos 348 , em uma lista de espera que ficou classificada em ordem decrescente pelo coeficiente. Dos participantes, entre os meses de março para junho, houve uma média de 60 alunos que desistiram do projeto, alguns relataram a desistência por sobrecarga, já que alguns trabalhavam e outros estudavam de segunda a sexta, outros por não conseguir acompanhar os conteúdos. Conforme previsto no edital realizou-se a segunda chamada de mais 60 alunos, e finalizando com uma lista de espera de 288 alunos.

O projeto teve como programação reuniões entre bolsistas, reuniões entre bolsistas e coordenadores, horários de atendimentos dos bolsistas para os estudantes do projeto e aplicação de 4 simulados, que diante das dificuldades financeiras da instituição só foi possível a aplicação de 01 simulado.

\section{FUNDAMENTAÇÃO TEÓRICA}

Dado que, em outubro de 2016 a Folha de São Paulo (SADAÑA, 2016), divulgou um gráfico onde compara o IDEB (Índice de Desenvolvimento da Educação Básica) das escolas públicas com uma pontuação média de 3,1 e com as privadas tendo uma pontuação de 5,7 , podemos ver uma diferença de mais de 


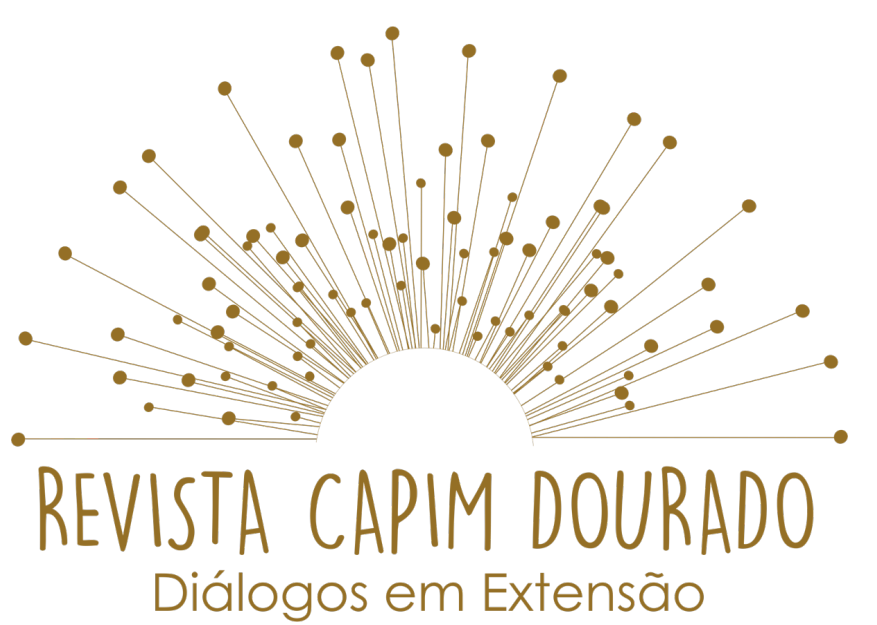

ISSN n² 2595-7341

Vol. 3, n. 1, Janeiro-Abril, 2020

DOI: http://dx.doi.org/10.20873/uft.2595-7341.2020v3n1p173

2 pontos no rendimento escolar dos alunos. Tendo isso em vista, e com o intuito de integrar o máximo de estudantes possíveis da rede pública de ensino, podendo oferecer a oportunidade para a preparação até o ENEM, visto que muitos desses estudantes não têm acesso a rede de ensino privada, que pela informação da Folha de São Paulo as redes de ensino privada tem um melhor desempenho, o projeto vem para oferecer o acesso à universidade para estes estudantes da rede de ensino pública.

Com isso, pensando em incentivar a permanência e a melhora do rendimento escolar dos estudantes, foi adotado como processo seletivo a avaliação do rendimento do histórico escolar do último ano letivo do ensino médio do participante, classificando em uma ordem decrescente. Já para a elaboração dos materiais pedagógicos, o projeto trabalhou em parceria com a plataforma App Prova (2017; 2018), nos fornecendo dados de infográfico com conteúdo mais cobrados no ENEM de 2009 a 2017 e com os materiais dos conteúdos e habilidades mais cobradas e erradas do ENEM. Com esses materiais a metodologia das aulas de cada disciplina ficou a critério individual de cada bolsista, realizando algumas reuniões entre bolsistas para troca de experiência, além da pesquisa realizada com 71 estudantes do projeto, reunindo dados dos estudantes e fazendo um levantamento sobre a estrutura do projeto, sobre a metodologia dos bolsistas em geral, sobre o desempenho de cada bolsista, sobre os conteúdos ministrados e um levantamento de sugestões para o projeto, tornando possível uma melhor leitura do projeto oferecido. 


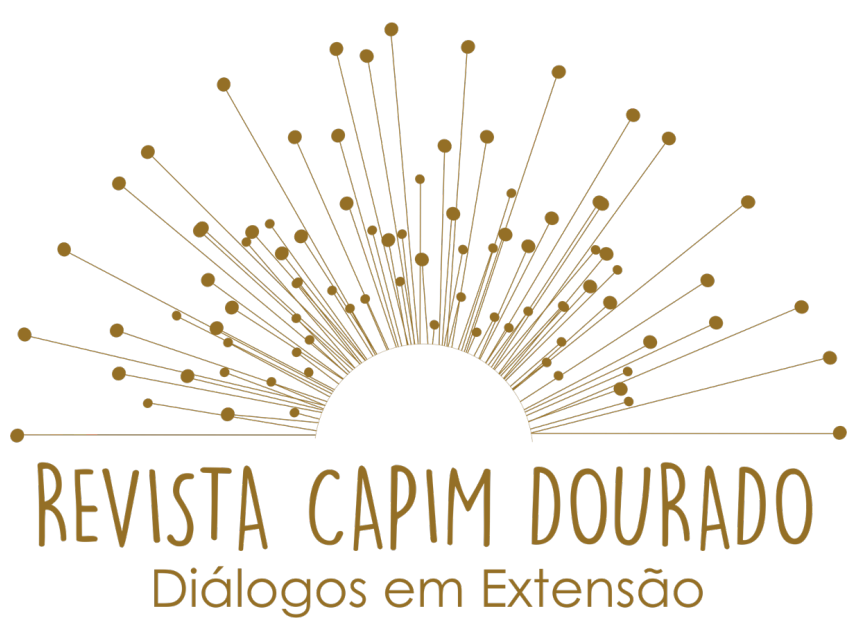

ISSN n² 2595-7341

Vol. 3, n. 1, Janeiro-Abril, 2020

DOI: http://dx.doi.org/10.20873/uft.2595-7341.2020v3n1p173

\section{RESULTADOS}

$\mathrm{Na}$ intenção de conseguir oferecer uma melhor preparação e acompanhamento para os estudantes desse projeto, foi aplicado 1 simulado, que foi de total importância para preparação dos estudantes do projeto, e para os professores bolsistas e voluntários que puderam ter um parâmetro para medir os pontos principais a serem ainda mais revisado em sala. Além do simulado, foi aplicado um questionário, e neste tivemos a resposta de 71 estudantes, sendo que desse total $48 \%$ dos estudantes já tinham terminado o ensino médio os outros $52 \%$ ainda estavam no terceiro ano, $18 \%$ desses estudantes trabalhavam, e em questão de dedicação aos estudos em uma escola de 0 a 5, 53\% dos estudantes se deram nota 4, $26 \%$ nota 3 e apenas $17 \%$ se deram nota 5 , podendo perceber um bom nível de interesse por parte do público estudantil do projeto em querer estudar e se preparar para as provas de vestibulares, ainda nesse questionário $61 \%$ dos estudantes avaliaram dizendo que a metodologia que os professores do projeto utilizavam era boa, e que eles estavam sempre conseguindo acompanhar as aulas, tendo assim um ótimo resultado do esforço e dedicação dos professores bolsistas e voluntários nesse projeto. Por tanto, pode-se concluir que a experiência dos bolsistas obtidas com esse projeto foi de fundamental importância para sua formação profissional como futuros docentes.

\section{CONSIDERAÇÕES FINAIS}




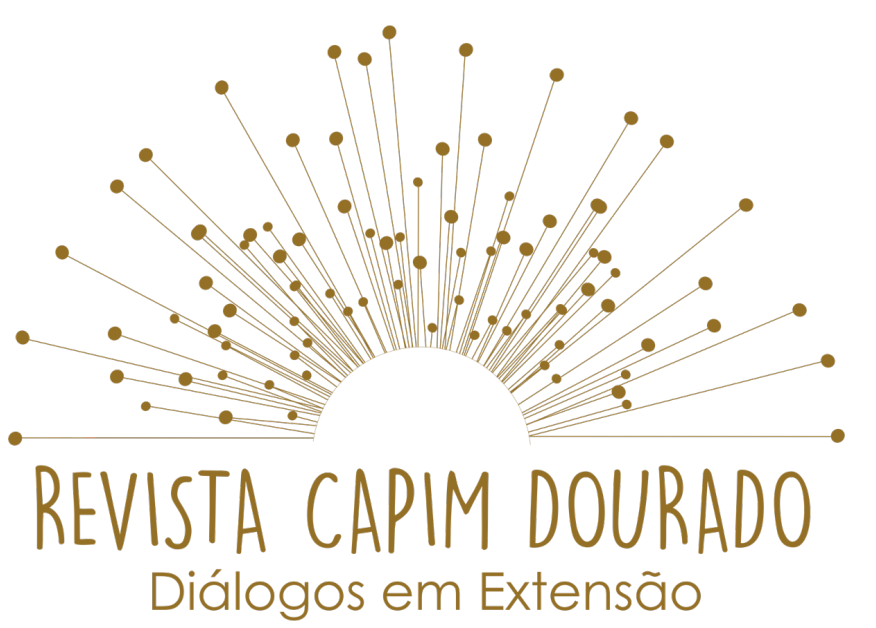

ISSN n² 2595-7341

Vol. 3, n. 1, Janeiro-Abril, 2020

DOI: http://dx.doi.org/10.20873/uft.2595-7341.2020v3n1p173

Durante todo o projeto, todos tiveram muitas dificuldades, tanto na perspectiva dos bolsistas, voluntários e dos estudantes desse projeto. Inicialmente, uma das dificuldades era a quantidade baixa de bolsas que foram oferecidas pela Pró-reitora de Extensão, através do Programa de Acesso Democrático à Universidade, sendo que o cursinho precisaria atender um total de 12 disciplinas e 13 professores(as), sendo essas disciplinas: História, Geografia, Sociologia, Filosofia, Química, Biologia, Física, Matemática, Literatura, Português, Redação e Língua estrangeira, sendo que precisaria de pelo menos 2 professores(as) de matemática devido a carga horário e o seu peso para os vestibulares e ENEM, além disso, precisaria de mais 2 pessoas para trabalhar na parte de apoio aos professores como monitores, para ajudar com equipamentos antes das aulas, organização da sala com os estudantes, entrar em contato com estudantes ou responsável em caso de falta e fazer acompanhamento individual dos estudantes. Porém, só foi possível trabalhar com 8 disciplinas, e 11 professores, sendo que desse total 4 eram voluntários e nem sempre estavam totalmente disponíveis para o projeto por não serem remunerados e os professores ainda precisavam correr atrás de toda estrutura de objetos de aula, como: datashow, notebook, extensão de energia etc. Perdendo as vezes de 10 a 15 minutos de aula, as vezes até mais, por faltar apoio de monitores. O projeto cursinho pré-enem comunitário PADU de Araguaína, aguardamos que haja novos investimentos por parte da Pró-Reitora de Extensão e Assuntos Comunitários, tendo em vista o impacto positivo em relação a comunidade de Araguaína e acadêmica do campus. Havendo um número maior de bolsas e mais 


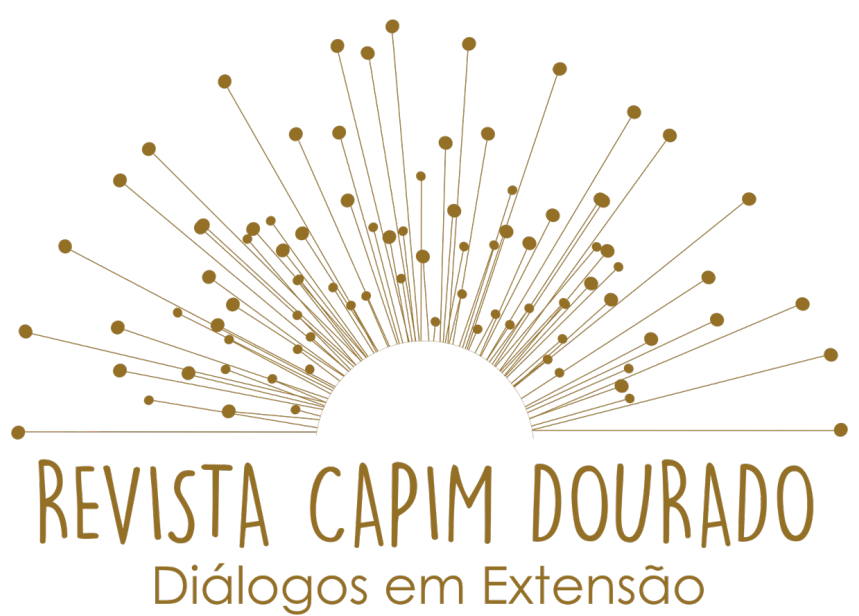

ISSN n² 2595-7341

Vol. 3, n. 1, Janeiro-Abril, 2020

DOI: http://dx.doi.org/10.20873/uft.2595-7341.2020v3n1p173

investimentos para aplicar simulados trimestralmente e ofertar oficinas de formação durante a semana, acredita-se que os resultados e os impactos tende a crescer exponencialmente.

\section{REFERÊNCIAS}

APPPROVA. PRINCIPAIS ERROS E ACERTOS NO ENEM. [S. l.], 2017. Disponível em: http://appprova.com.br/wp-content/uploads/2017/06/APP0675__Infogr\%C3\%A1fico_Principais_Erros_e_Acertos_G_Linkado.pdf. Acesso em: 12 fev. 2018.

SALDANÃ, Paulo. Vestibular ditará reforma do ensino médio em escolas particulares. Folha de S.Paulo, 2016. Disponível em: https://www1.folha.uol.com.br/educacao/2016/10/1821222-vestibular-ditarareforma-do-ensino-medio-em-escolas-particulares.shtml. Acesso em: 7 fev. 2018.

SOMOSPAR. Conteúdos e Habilidades mais cobrados do ENEM. [S. l.], 2018.

Disponível em: https://www.somospar.com.br/wpcontent/uploads/2018/07/infografico-conteudos-e-habilidades-mais-cobradosdo-enem-atualizacao-2009-a-2017.pdf. Acesso em: 31 mar. 2018.

UNIVERSIDADE FEDERAL DO TOCANTINS. Edital de abertura de inscrições para selecionar candidatos a bolsista para atuar no Programa de Acesso Democrático à Universidade. docs.uft.edu.br, 2018. Disponível em: 


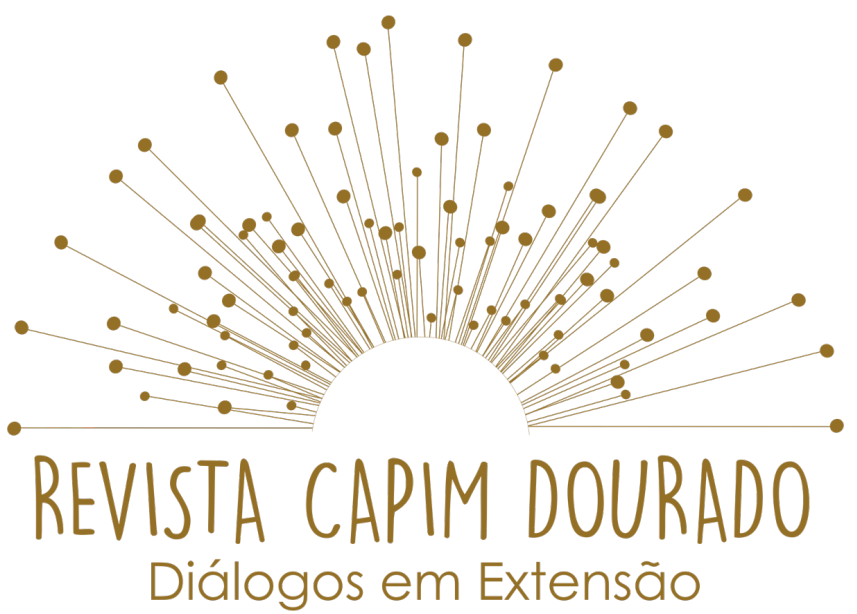

ISSN n² 2595-7341

Vol. 3, n. 1, Janeiro-Abril, 2020

DOI: http://dx.doi.org/10.20873/uft.2595-7341.2020v3n1p173

https://docs.uft.edu.br/share/s/A0FFk6zzR0evUww8cNCYcQ. Acesso em: 17 maio 2018. 